\title{
Impact of IoT on Smart Cities
}

\author{
Vivek Veeraiah, G. K. Ravikumar
}

\begin{abstract}
It's been an era of ever-emerging globalization, and the integration of world economies has been the new norm that has caused immense expansion and rapid urbanization. The phenomenon has many flaws tangled. Governments globally use IoT-enabled solutions to build smart cities for better efficiency and management of cities to encounter the constraints. Smart cities enabled IoT applications to provide comprehensive ranging solutions on a real-time basis. The researcher's objective is to comprehensively review how smart cities helped with IoT applications encounter challenges to practical real-time problems faced in cities. Smart cities enabled with IoT solutions are predominantly composed of Information and Communication Technologies (ICT). A protocol can be developed for sustainable development to address the facets of issues faced in cities due to pressure brought about by excessive and rapid urbanization caused by push factors.
\end{abstract}

Keywords: Internet of Things, Smart cities, Push factors of

\section{INTRODUCTION}

The Internet of Things can refer to a network of the interconnection of objects with embedded systems, which leads to a distributed interconnections of networking devices that communicate with human beings and other devices as desired. IoT has gained momentum and has opened opportunities for novel applications. The Internet of Things can be regarded as a new and emerging paradigm that envisions the future and changes how public officials solve crucial urban setup problems. However, such a heterogeneous field of application identifies solutions capable of satisfying all possible application scenarios' requirements as a formidable challenge. This difficulty has led to the proliferation of different and sometimes incompatible proposals for IoT systems' practical realization. Therefore, from a system perspective, the culmination of an IoT network, together with the required backend network services and devices, still lacks an established best practice because of its novelty and complexity. In addition to the technical difficulties, the IoT paradigm's adoption is also hindered by the lack of a clear and widely accepted business model that can attract investments to promote these technologies' deployment. Reference [1] Smart cities: The concept of a smart city has no universal definition. A smart city is an urban area that uses different electronic devices and sensors to collect critical data for better city management.

Manuscript received on May 21, 2021.

Revised Manuscript received on September 04, 2021.

Manuscript published on September 30, 2021.

*Correspondence Author

Vivek Veeraiah*, Department of R\&D, Computer Science, BGSIT, Adichunchanagiri University, Karnataka, India. E-mail: vivek@amc.org.in

Dr. G. K. Ravikumar, Department of R\&D, Computer Science, BGSIT, Adichunchanagiri University, Karnataka, India E-mail: ravikumargk@bgsit.ac.in

(C) The Authors. Published by Blue Eyes Intelligence Engineering and Sciences Publication (BEIESP). This is an open access article under the CC BY-NC-ND license (http://creativecommons.org/licenses/by-nc-nd/4.0/) urbanization, economic development, IoT Architecture.

It utilizes technology and enhances efficiency by making use of IoT embedded systems. Pike Research on Smart cities, the smart city market is estimated at hundreds of billion dollars by 2022. Reference [2] Complexities of urbanization due to push factors have resulted in the migration of the population from rural to urban areas, causing immense structural deformity. (Difficulties faced in rural areas forces population to move to urban areas in search of livelihood). A technology-driven solution to facets of problems caused due to urbanization has been the mandate. Smart cities are predominantly composed of Information and Communication Technologies (ICT), which aids in developing a protocol and promotes sustainable development to address urbanization challenges.

Information sharing: The smart city concept integrates information and communication devices mapped with IoT applications to manage the urban flows in real-time.

Urban IoT Architecture: There is no single consensus on architecture for smart city IoT, universally accepted. It is a multi-layered architecture that is centralized with decentralized limited powers. There is a dense and heterogeneous set of devices deployed over the urban area generating different data types. An urban IoT infrastructure integrates various technologies, integrates many devices and communication applications.

Smart city IoT Architecture:

\begin{tabular}{|c|}
\hline Public utility layer \\
\hline Business domain layer \\
\hline Knowledge layer \\
\hline Application layer \\
\hline Security layer \\
\hline Processing layer \\
\hline Transportation layer \\
\hline Network layer \\
\hline
\end{tabular}

A real-time, practically oriented solution is the need for the hour to counter various urban setup problems.

The concept of a smart city can thrive and bring about economic development in a sustainable manner using IoT embedded systems. Information and communication (ICT) solutions mapped with smart devices connected via the internet have brought about a revolution in dealing with urban development problems and the evolution of the emergence of smart cities.

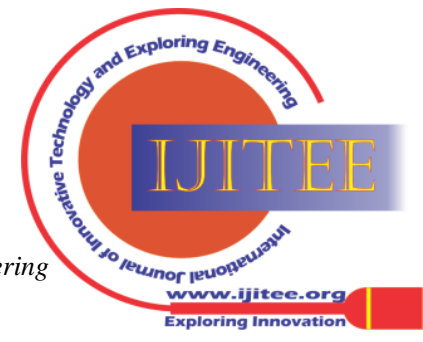




\section{Impact of IoT on Smart Cities}

Globally, governments have analyzed the potential benefits arising from IoT, which can be applied to public policies. Reference [3] In May 2014, The Korean government published its plan for building the IoT to hyper-connected, "digital revolution" to address policy goals. Among the purposes is to attain IoT-driven economic development. Some examples already visible are Songdo Smart City and Smart eel farms. It targets the commercialization of $5 \mathrm{G}$ mobile communications by 2020 and aims for Gigabit Internet to achieve $90 \%$ of national coverage by 2017 ; it has been completed as the need of the hour.

The introduction of IoT services nationally can cause hindrance and conflicts with the existing regulations, leading to bottlenecks. A network can be developed to optimize the efficiency and improve the effectiveness of city operations and services. Smart City enabled IoT technology to evolve as a result-oriented approach for enhanced city infrastructure with reduced cost to the exchequer.

Worldwide public officials are trying to find an automated real-time solution. "Anytime, anywhere" approach is required to tackle the wholesome problems of making a foolproof smart city. The likes of the developed and the developing economies can be used in the smart city enabled with IoT technology for various purposes: Production and distribution of goods and services, optimum utilization of available resources, and solving the central problems of an economy. Reference [4]

The United States government also hosted a forum coinciding with smart cities week, highlighting new steps and brainstormed additional ways that science and technology can support municipal efforts. The forum included creating testbeds for IoT/ applications and big data analytics, intending to help the United States companies become global leaders in this field.

Government and public officials analyze tradeoffs and scarcity of essential commodities making use of IoT embedded systems. Collection and analysis of data play a crucial role. Real-time data collection can be possible by making use of IoT-enabled systems.

\section{PRODUCTION POSSIBILITY CURVE}

The curve is also known as the transformation curve or the production possibility frontier. The PPC can be defined as a curve plotted on a graph that shows all of the different combinations of output that can be produced, given that technology and resources remain constant. Consider two types of goods are produced: wheat and cotton

\begin{tabular}{|l|l|l|l|}
\hline $\begin{array}{l}\text { Production } \\
\text { possibilities }\end{array}$ & $\begin{array}{l}\text { Cotton } \\
\text { (thousand } \\
\text { meters) }\end{array}$ & $\begin{array}{l}\text { Wheat } \\
\text { (thousand } \\
\text { meters) }\end{array}$ & $\begin{array}{l}\text { Opportun } \\
\text { ity cost }\end{array}$ \\
\hline A & 0 & 15 & 1 \\
B & 1 & 14 & 2 \\
C & 2 & 12 & 3 \\
D & 3 & 9 & 4 \\
E & 4 & 5 & 5 \\
F & 5 & 0 & \\
\hline
\end{tabular}

Opportunity cost refers to the cost of the sacrifice of the following best alternative.
The above table shows various production possibilities between cotton and wheat. It is clear from the above information if all the given resources are employed for the production of wheat, 15,000 quintals of wheat are produced in an economy. Respectively, if all the resources are utilized in cotton production, 5000 cotton meters are produced. These two are extreme production possibilities. There are many other production possibilities between these two points, like B, C, D, and E.

It can be concluded that an economy is moving from one possibility to another, and it will take away few resources from wheat and put it in the production of cotton. It can be noted that resources are limited and assumed that they are fully employed; thus, the economy has to give up or sacrifice something of one good to obtain some more of the other.

The above information can be obtained on a real-time basis, and the system has to be automated. Public officials can make use of IoT embedded systems.

\section{Smart city beset with IoT enabled application has wide- ranging uses}

For a sustainable future in Smart cities, public officials need to focus on fitting technologies. India has used the smart city community cloud, which aids in transforming the urban setup and revolutionizing the economy. It will turn out to be a citizen-centric approach. Urban IoTs are designed and formulated to support the Smart city vision. Collaboration of various systems such as smart parking, crime in check, etc.

1. Road traffic jams: Smart traffic solutions managed with IoT enabled application uses a different type of sensors and captures GPS data from driver's smartphones to determine the number, location, and speed of vehicles. This would keep the security, safety measures, and simultaneously, smart traffic lights will be connected to a cloud management platform that monitors the green light timings and automatically alters the lights based on the current traffic situation to prevent congestion.

2. Crime in check: Smart cities enabled with IoT applications can detect and track criminals on a realtime basis. Terrorism and criminal events have plagued society and have been a significant cause of concernthe exploitation of smartphone devices combined with a layered computation and communication-based networking. Due to the growing diffusion of connected mobile devices mediated by the network, it is possible to establish collaborations, share data, provide real-time information on specific events, as well as to perform on-site computation by moving towards smarter cities.

3. Smart parking: Parking in congested urban areas has been a menace for a place to park a vehicle, time is taken, and security parameters. By using IoT-enabled innovative applications and GPS data from the driver's smartphone or surface of the road sensors automated and embedded in the ground mapped to the parking spots, the driver can track and determine if a parking spot is already occupied; time is taken to get the parking spot. This brings a real-time parking solution. 
The drivers will receive a notification as the system is in the loop and is mapped.

4. Heritage buildings: Heritage buildings that are historical need continuous monitoring. Natural calamities and harsh conditions like stress to the building, pollution can cause severe damage to the building, thus checking the time and again. An urban-based IoT platform provides real-time information from the sensors placed near the desired locations, which would be very expensive for human operators to check the building's structural architecture.

5. Waste management: With rapid urbanization and the expansion of cities, waste management plays a pivotal role concerning cleanliness, hygiene, and control of contiguous diseases. Governments globally are looking out for technologies to combat concerns with waste management and disposal of waste. Removal and storage of waste in landfills have brought about stress on the land. Hazardous waste has to be disposed of with precaution, else would hamper the environment and cause health problems to humans. ICT and IoT solutions in this domain will efficiently reduce waste management and reduce associated economic costs. The devices can be connected with sensors, and an intelligent waste container can be developed, which provides real-time information of the truck fleet of waste disposal mechanism. IoT-enabled waste collection and transportation can be advantageous in the implementation of waste management.

6. Smart parking: IoT-enabled smart parking makes use of road sensors and intelligent displays. This would drastically reduce the time taken to park a vehicle and determine a vacant spot to park the vehicle. This will drastically reduce traffic congestion.

7. Noise pollution: In India, Swachh Bharat Abhiyan has set up the National Air Quality Index, monitored by the Ministry of Environment. The air quality index comprises eight pollutants (PM10, PM2.5, No2, SO2, CO, O3, NH3, and PB). The Central Pollution control board monitors the National Pollution control board, the Ministry of Environment, forests, and climate change. The air pollution results are monitored on a real-time basis and are embarked with color codes and health impacts respectively for the states. Reference[5]

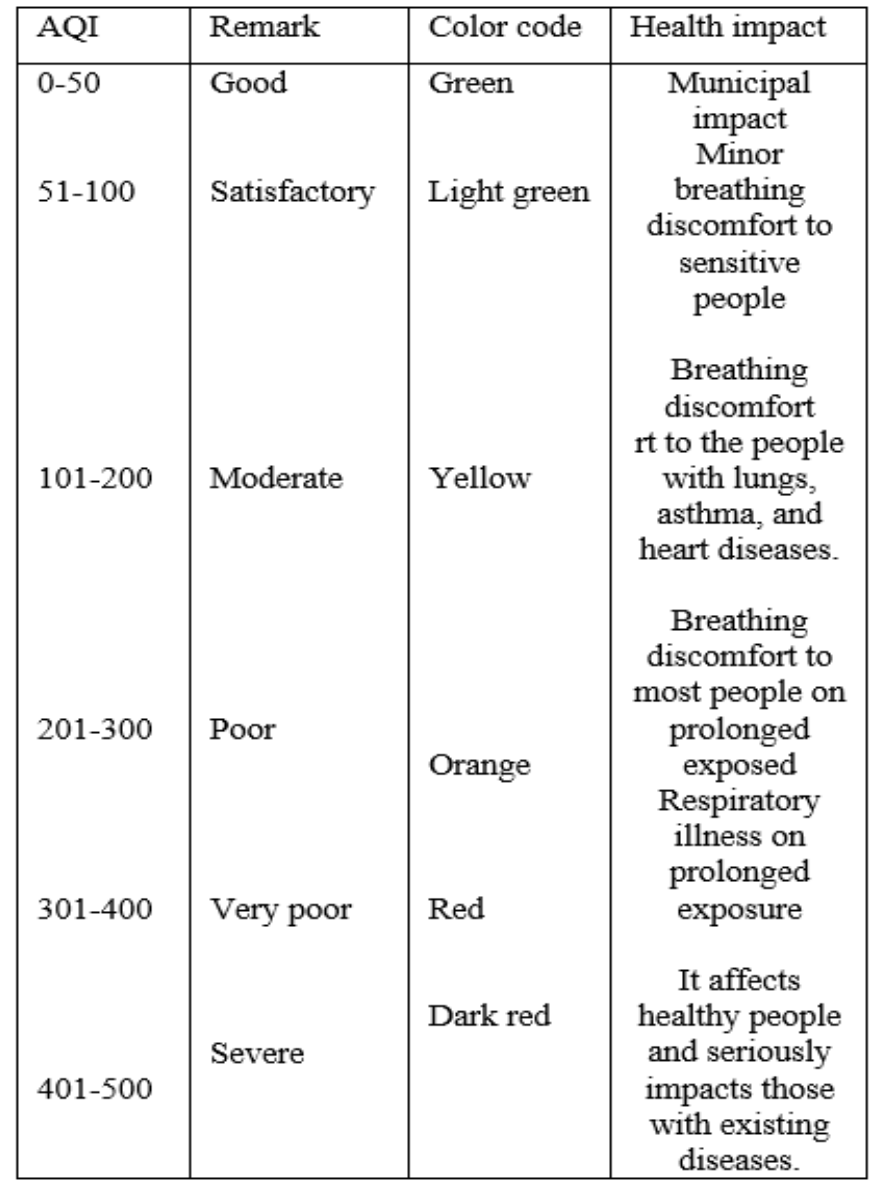

Public officials can use the Urban IoT platform to gather data on a real-time basis and act accordingly.

Smart Cities Mission with specific reference to Indian context: The National Smart Cities Mission was launched in 2015. The Union Ministry of Housing and Urban Affairs is implementing the mission in collaboration with the respective state governments. The mission initially included 100 cities, and the deadline for the completion of the projects has been set between 2019 and 2023. It is a five- year program where the respective state government would nominate one city for the Smart City Challenge. Each city will create a particular purpose vehicle headed by a full-time CEO to implement the smart city. Reference [6]

Published By:

Blue Eyes Intelligence Engineering and Sciences Publication

(C) Copyright: All rights reserved.

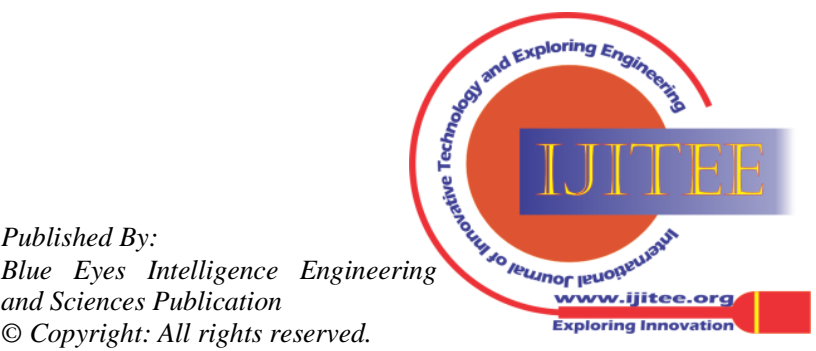




\section{Impact of IoT on Smart Cities}

Open data platform: (India Smart Cities) "Smart cities continuously strive towards making the right data available to the right people at the right time to help build solutions to complex urban challenges. With the deployment of IoT devices and other methods to sense the city, real-time data is increasing every day, offering cities the chance to address these challenges in smarter ways. It intends to harness this potential through its 'Data Smart" Cities strategy.

\section{CONCLUSION}

Smart city with urban IoT platform has changed how we live life in an urban setting. From crime to traffic congestion, the IoT platform has been a path-breaking innovation to address the public's grievances in a timebound manner; a holistic approach has been the norm for sustainable development. It has been a citizen-centric approach. Smart cities, with the help of IoT and cloud architecture, IoT (Social Internet of Things, BIoT (Business Internet of Things), and IoT(Knowledge Internet of Things), will provide a seamless edge over the present technology in fast forward time crunching ultra-modern world.

\section{REFERENCES}

1. A. Laya, V.I Bratu, and J.Markendahl .'Who is investing in machineto-machine communications? In Proc 24 ${ }^{\text {th }}$ Eur.Reg. ITS Conf., Florence, Italy, Oct 2013, pp.20-23)

2. Pike research on the smart city (online). Available: https;//www.pikeresearch.com/research/smart-cities.)

3. OECD digital economy papers 2016 ministerial meeting )

4. : :/www.whitehouse.gov/the-press-office/2015/09/14/fact-sheetadministration-announces-new-smart-cities-initative-help

5. https://app.cpcbccr.com/AQI_India/

6. https://smartcities.data.gov.in/

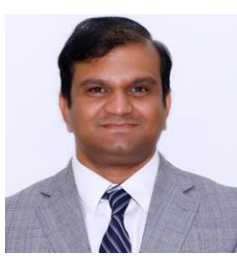

\section{AUTHORS PROFILE}

Vivek Veeraiah is a Research Scholar of Computers Science Department, BGSIT, Adichunchanagiri University, Karnataka, India. He received his B.E. degree in Electronics and communication from Visvesvaraya Technological University (VTU), India, in 2006, M.S. degree in Computer Science from New York University, USA in 2009 and MBA in Innovation and Technology Management from New York University in 2010. He was an Adjunct Professor and Administrative Director of Technology Management Division of New York University School of Engineering from 2009 to 2017. His research interests include Internet of Things, Computer Network, Entrepreneurship, Social Entrepreneurship, Innovation and Technology Management. At present, $\mathrm{He}$ is engaged in IOT and Social Entrepreneurship for developing countries.

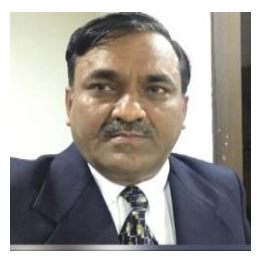

Dr. Ravikumar G. K received his B.E. degree from Bangalore University, India in 1996, M.Tech Degree in Computer Science from National Institute of Technology Karnataka, formerly known as Karnataka Regional Engineering College, Surathkal India in 2000 and he obtained his $\mathrm{PhD}$ in Information Technology from MGR University Chennai in 2011. He was working as Assistant Professor and HOD for Department of Computer Science at SJBIT Bangalore during 2001 to 2006, He worked as Technical specialist at iGATE Global solutions Bangalore during Dec 2006 to Jun 2010. Later he moved to Wipro Technologies as Program manager and served for 2 years then moved to Acharya Institute of Technology as Professor in the Department of Computer Science and worked for 2 years, later he moved back to Wipro as Principal consultant and worked more than 6 years and currently he is working as Director - Students Welfare, IT Head, IP-Cell Chief: Coordinator, R\&D Head (Department of Computer Science \& Engineering), BGSIT, Adichunchanagiri University BG Nagar. Mandya, Karnataka 571418, India. His research interests include Data Mining, Data Masking, Big Data analytics and Blockchain with AI \& ML.

He has guided 4 Ph.D students in computer science under Visvesvaraya Technological University is a collegiate public state university in Belagavi, Karnataka, India. Currently he is guiding students at Adichunchanagiri University and VTU. He has published 70 plus research article in various national and international journals \& he has filled 10 patents in the area of Big Data and Analytics. He is an active reviewer for various international journals and he a life member for various professional bodies like CSI, FIE, IEEE etc.
Published By:

Blue Eyes Intelligence Engineering and Sciences Publication

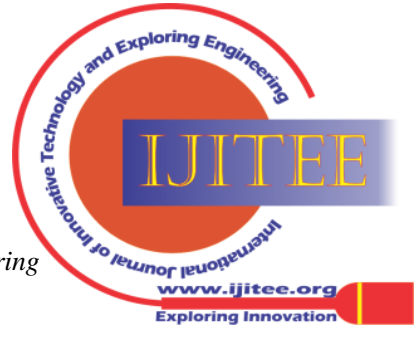

